\title{
A Dissociação da Autoria em Literatura Contemporânea: Graça Infinita $e$ House of Leaves
}

Bruno Nogueira

\author{
RESUMO - O ensaio busca traçar uma conexão entre: 1) o desenvolvi- \\ mento de tecnologias de informação contemporâneas e a configuração \\ societária subjacente, na esteira teórica da sociedade em rede de Manuel \\ Castells; 2) as bases filosóficas e estéticas de dois autores americanos- \\ David Foster Wallace, Mark Z. Danielewski e suas respectivas obras Gra- \\ ça Infinita (1996) e House of Leaves (2000); e 3) determinadas qualidades \\ da recepção da obra pelos leitores, onde a Internet é uma importante fer- \\ ramenta para incrementar a experiência literária. A relação entre os três \\ pontos culmina no conceito de "hermenêutica neorromântica": apreender \\ sentidos literários não apenas na sua relação simbólica com o autor, mas \\ com uma comunidade virtual que produz "paratexto" (adições interpreta- \\ tivas ao texto original) \\ Palavras-Chave: Graça Infinita; Hermenêutica Neorromântica; House of \\ Leaves; Paratexto; Sociedade em Rede.
}

ABSTRACT: The purpose of the essay is to draw a connection between 1) contemporary information technology development and its related societal structure, following Manuel Castells theory of network society; 2) the philosophical and aesthetical foundations of two American authorsDavid Foster Wallace, Mark Z. Danielewski and their respective works Infinite Jest (1996) and House of Leaves (2000); and 3) certain qualities of the works reception by the readers, in relation to the importance of the Internet in enhancing literary experience. The connection between the three points gives way to the developed concept of "neoromantic hermeneutics", i.e. the apprehension of literary meanings not only by a symbolic relationship with the author, but also with an online community of "paratext-makers" (interpretive additions to the original text).

Keywords: House of Leaves; Infinite Jest; Neoromantic Hermeneutics; Network Society; Paratext. 
Quando eu queria ler Freud, precisava ir à única biblioteca em Barcelona com acesso à sua obra e preencher um formulário explicando o porquê.-—Manuel Castells

O desenvolvimento de diversas tecnologias comunicacionais e sua consequente absorção pelas massas-televisão e Internet-a partir dos anos 50 tiveram consequências significativas no mundo da ficção literária. Os dois escritores discutidos aqui, David Foster Wallace e Mark Z. Danielewski, tiveram relações íntimas com a mídia audiovisual. As duas obras tratadas, Graça Infinita (de 1996) e House of Leaves (de 2000), estão relacionadas com o impacto da Era da Informação na vida cotidiana: elas abordam a relação entre mídia, comunicação e identidade. A proposta do ensaio é explorar a ideia de sociedade em rede e suas consequências para a subjetividade no século XXI no âmbito das obras referidas, no lado dos autores, que configuram suas obras baseados em suas vivências na Era da Informação, e no lado dos leitores, que têm sua experiência literária modificada pelas tecnologias — onde a noção de paratexto, i.é, conteúdo que expande o universo semiótico de uma obra, é crucial. O ensaio motiva-se ao lançamento da ideia de hermenêutica neorromântica para denotar uma forma específica de interpretação de texto que se desenvolve na Era da Informação, permeando por grupos online de fãs por meio da produção e acesso de conteúdo na internet: "o sentido como volição do autor mais sentidos levantados no paratexto".

\section{0. (semificção)}

"R: Eu estava em minha casa, ou em meu trabalho, um desses dois locais, tenho certeza. São lá que uso a internet para acessar o meu e-mail. Eu estava com o Gmail aberto em meio a vários outros sites, como sempre faço. Minha mãe é o que pode se chamar de entusiasta cultural e faz questão de expor sua verve para os filhos e pessoas próximas, para tentar despertar interesse. Ela sempre me manda e-mails com links para sites de que ela gosta; desta vez não tinha sido diferente. O link era pra um vídeo do Youtube, 'David Foster Wallace on Ambition', de um canal que faz animações para entrevistas consagradas, o Blank on Blank. Achei interessante e acho que já tinha ouvido falar do Foster. Vi o vídeo e gostei e então acessei a Wikipédia em inglês do cara; vi que a magnum opus se chamava Infinite Jest. Não muito tempo depois, encontrei o livro à venda na Livraria Cultura e acabei comprando. Também achei num site uma versão .mobi, que é pro Kindle; baixei e foi muito útil pra quando eu não podia carregar a chaproca de cinco quilos comigo.

P.

R: Foi difícil ler em inglês, há várias palavras de uso raro tanto oral quanto textualmente. Pelo menos minha língua nativa ser de origem latina ajudou porque, você sabe, certas palavras rebuscadas em inglês são de origem latina e para nós nem são rebuscadas. Enfim, sobre sua pergunta: durante a leitura eu acessava uma wiki - é como se chamam sites enciclopédicos de edição aberta e anônima em inglês especialmente feita para o livro, um guia página a página

Dossiê Multimodalidade da Memória: Narrativa e Teoria Social

Arquivos do CMD, Volume 4, N.1. Jan/Jun 2016 
Ajudou muito para entender referências à cultura pop norteamericana e tal, e além do quê não continha spoilers.

R: Depois de ler tudo eu acessei uma cacetada de sites. Blogs, imagens do Google, fóruns (o Infinite Summer), vídeos do Youtube. Aprendi muita coisa sobre o livro com esses sites. Só tenho a agradecer a essas pessoas anônimas que leram o livro no mínimo duas vezes, acredito, e daí se puseram a publicar na internet uma série de informações e teorias sobre a narrativa. Sem a internet, eu teria que ler o livro de novo, talvez. Acho que chegaria a outros lugares lendo o livro de novo em vez de ler fan-theory. Mas o conteúdo online secundário já rendeu uma experiência satisfatória.

P.

R: Sim, cheguei até House of Leaves num dia quando procurei pelas palavras 'Infinite Jest Lovecraft' no Google. Foi por causa de um capítulo em específico do livro, essa procura. O primeiro site era uma materia de nome 'The Temptation of the Unfilmable: 7 Books That Should Never Hit the Silver Screen', e não por acaso estava lá o do Foster e um do Lovecraft, o Nas Montanhas da Loucura. E por acaso o House of Leaves estava lá também."

\section{1. (literatura e sociedade em rede)}

A viabilidade artística do pósmodernismo foi uma consequência direta não de novos fatos sobre a arte, mas de fatos sobre a nova importância da cultura de massas comercial. Americanos pareciam não mais unidos por crenças em comum, mas por imagens em comum (FOSTER WALLACE, 2014 [1990], p. 675, trad. nossa)

Para compreender sociologicamente a influência da/na literatura da/na Era da Informação (doravante EI), recorro a Manuel Castells e à concepção, já bem firmada na teoria social, de poder como uma relação que envolve socialmente os agentes e se origina numa relação assimétrica entre as partes, não estando "localizado em uma esfera ou instituição em particular: distribui-se através de todo o reino da ação humana" (CASTELLS, 2010, p. 15). A relação entre poder, produção literária e consumo de literatura está presente na maneira como a sociedade pós-industrial da EI influencia na criação de estilos e conteúdos literários, como também no sucesso comunicativo e modo de consumo de obras como as em foco: Graça Infinita, de David Foster Wallace (DFW; 1962-2008) e House of Leaves, de Mark Z. Danielewski (MZD; 1966-). Autores carregam para suas obras uma carga cultural relacionada ao microcosmo em que vivem-eles também estão submetidos a relações de poder que acabam por configurar a performance da escrita criativa. Há uma dialética cultural entre a produção literária e seus resultados nas mentes dos leitores, o poder sendo a locomotiva.

Apesar de tais conceitos denotarem fenômenos por vezes bastante fluidos e difíceis de perceber, o advento da EI foi uma mudança em larga escala que trouxe novidades conspícuas—seu alcance

Dossiê Multimodalidade da Memória: Narrativa e Teoria Social 
global é uma das razões para o impacto transnacional da ficção norte-americana de DFW e MZD, seja porque os leitores estão emocional e conscientemente sujeitos à mudança cultural provocada pela EI, seja porque a própria EI proveu o grande recurso de contato com tais obras: a internet.

Antes de alcançar essa globalidade, o desenvolvimento de tecnologias de informação e comunicação nos Estados Unidos durante os anos 50 e 60, baseadas em microeletrônica, alavancou a EI primeiro nos EUA nos anos 70 (CASTELLS, 1999a). Concomitantemente, em ficção literária o pós-modernismo norte-americano alcançava um status com obras como O Arco-Íris da Gravidade (Thomas Pynchon) e Ruído Branco (Don Delillo), que tratam dos temas da tecnologia e comunicação. No mapa do pós-modernismo, o texto e a linguagem são uma produção semiótica imanente, e a ideia de texto como mimesis da realidade é deixada de lado por uma ótica "literatura é uma forma de comunicação sui generis", podendo se utilizar de metaficção e modificar as regras autoimpostas na página seguinte_- “transitar entre ontologias” (ver MCHALE, 1987). A distinção entre realidade e simulação, isto é, a prefiguração de uma estrutura operacional transcendente, também vai se dissolvendo na filosofia continental e sociologia com o advento da EI, seja enquanto declaração sobre o status ontológico da sociedade (BAUDRILLARD, 1991), seja como proposta método-ontológica (LATOUR, 2005); ou então, como faz DFW em sua ficção, seja no fim de dualismos sociais do tipo central v. periférico e suas versões anteriores marxistas (pós-colonialismo). O mundo pós-estruturalista também é o mundo da ficção de DFW: "Wallace visualiza o espaço americano como um campo de jogo nivelado onde a mídia eletrônica opera em todas as zonas [centro v. periferia/urbano v. subúrbio no intra-EUA] simultaneamente" (GILES, 2007, p. 328).

A chamada sociedade em rede do século XXI denota um modo de vida extremamente conectado à internet, que vai progressivamente suplantando os demais veículos como a televisão e a mídia impressa. Apesar das redes serem um elemento inerente à ideia de sociedade, "foi por causa da informação eletrônica e tecnologias de comunicação disponíveis que a sociedade em rede pôde florescer por completo, transcendendo os limites históricos das redes como forma de organização social e interação." (CASTELLS, 2010, p. 24). As redes conectam pontos que podem estar muito distantes no espaçotempo kantiano - como quando se acessa um site da internet de uma década atrás feito por uma pessoa de outro continente-, e são constituídas por uma relação entre o global e o local, entre o "real por fora" e o "real por dentro" (ver Tabacaria, de F. Pessoa), entre as instituições e o inefável: na experiência literária, isso se dá pelo subjetivo exercício hermenêutico e estético de capturar/criar sentidos consumindo a obra, no lado do "local", e pelo mercado de tecnologias que colocam o bem simbólico-e a paratextualidade subjacente - diante do leitor no lado do "global".

O desenvolvimento dos sistemas de informação e comunicação resultou numa nova vivência social do espaçotempo, caracteri-

Dossiê Multimodalidade da Memória: Narrativa e Teoria Social

Arquivos do CMD, Volume 4, N.1. Jan/Jun 2016 
zada pelo desacoplamento da contiguidade e do compartilhamento de tempo. A conexão de pontos muito distantes espaçotemporalmente facilitou-se e encampa a formação da identidade contemporânea: os experimentalismos literários foram sujeitos dessa experiência tanto nos conteúdos tratados como na forma de abordá-los. Graça Infinita, por exemplo, possui uma narrativa não-linear que vai e volta a pontos específicos do espaçotempo de maneira semicaótica, além de possuir centenas de notas de fim que levam o leitor a ir e voltar ao fim do livro (no caso da versão física) e, sendo uma crítica ao entretenimento um dos principais temas do livro, decide acabar a história antes do clímax erguido ao longo de centenas de páginas; DFW ao longo de toda sua obra procurou enquadrar seus personagens num mundo pós-humanista de convenções sociais voláteis ${ }^{1}$ (GILES, 2007). House of Leaves decide dar ao leitor a decisão de quem escreveu o livro homônimo dentro do livro e de quais personagens de fato existem: a experiência literária está submetida à discricionariedade ontológica do leitor. Os mecanismos de ambas as obras estão contextualizados numa sociedade de interconectividade e saturação de informações onde a tentativa de representar essas características num romance apela a determinados consumidores- $\mathrm{O}$ entretenimento não serve apenas para fugir da realidade, mas também para ajudar a entendê-la: a geometria polimórfica do fluxo de informações na EI convida a estruturas narrativas heterodoxas ou ao menos as torna menos alienígenas.
O que caracteriza a sociedade em rede global é a contraposição entre a lógica da rede global e a afirmação duma multiplicidade de sujeitos locais [...] A pergunta-chave que surge é sobre a capacidade das identidades culturais específicas [...] de comunicarem-se. [...] A cultura global é uma cultura de comunicação em prol da comunicação (CASTELLS, 2010, p.37-38 - tradução e ênfase nossa).

O entrelaçamento de várias culturas locais e a reação dos indivíduos à dialética global-local torna-se questão social de grande peso na EI. Se por um lado povos podem se tornar mais globais, por outro pode haver uma reação de fechamento perante culturas tidas como estranhas e forasteiras-tribalismo reacionário (Antonio, 2000; não por acaso, um dos personagens principais de Graça Infinita é fascista). Graça Infinita ensaia um futuro distópico de Estados Unidos hipercosmopolita, onde este gerou uma forma específica de tribalismo: o do indivíduo. Pois se há a convivência de várias culturas diferentes, um valor necessário é a tolerância. Mas o excesso e meios para ela ser exercida podem implicar numa limitação da comunicação entre pessoas - que emudece coisas subjetivas ou mi nimamente polêmicas justamente por terem essa qualidade_-; numa sociedade hipercosmopolita o excesso de subjetividade pode implicar numa falta de intersubjetividade, i. é, de valores e crenças compartilhados. O livro de DFW aponta para paradoxos do processo de globalização, porque ao mesmo tempo em que esta aproxima diversas culturas locais, ela vai gerando com isso uma cultura global onde os objetos de consumo suplantam a cultura como elemento formador da identidade (JAMESON, 1991), uma cultura "que muda

Dossiê Multimodalidade da Memória: Narrativa e Teoria Social

Arquivos do CMD, Volume 4, N.1. Jan/Jun 2016 
conspicuamente duma comunidade de relações para uma rede de desconhecidos conectados por autointeresse e tecnologia" (FOSTER WALLACE, 2014, p.660 - tradução nossa) com fronteiras intersubjetivas possivelmente sufocantes. O personagem Mario Incandeza de Graça Infinita representa o indivíduo em uma busca filosófica pelo sentido da vida que não encontra pares interessados em compartilhar com ele suas jornadas pessoais nesse caminho, ou que compartilham somente porque Mario não é visto como um indivíduo completo (ele possui deficiências mentais e físicas). Globalização e identidade são tendências conflitantes e "neste fim de milênio, o rei e a rainha, o Estado e a sociedade civil estão todos nus, e seus filhos-cidadãos estão vagando em busca de proteção por vários lares adotivos" (Castells, 1999b, p.418). O páramo pós-industrial, ao pôr em xeque conceitos de interpretação da realidade, torna o mundo da EI "menos sólido e mais líquido" (BAUMAN, 2001)—a literatura não se isola do processo:

A ficção de Wallace remete a um novo tipo de regionalismo americano, um menos predicado pelas distintas propriedades imanentes a qualquer local dado do que pelas cartografias relacionando "aqui" e "lá" a redes globais oni-influentes. (GILES, 2007, p. 341 - tradução nossa)

\section{1 (paratextualidade na Era da Informação)}

O uso de materiais secundários como recurso extra de consumo de bens literários não é particular à EI: há tempos os leitores se voltam a críticas ou resenhas em mídia impressa, dicionários, grupos de discussão, livros-guia, aulas, círculos que trocam cartas etc. Defino aqui paratextualidade como quaisquer contribuições para a interpretação de um texto cuja fonte não seja o próprio texto e que envolva alguma comunicação.

Podemos elaborar que a diferença entre paratextualidade e conteúdo secundário é que o paratexto diversas vezes não é um complemento, mas uma soma interpretativa ao texto original. As fronteiras entre o que é uma mensagem do texto original e o que é do paratexto são bastante fluidas, ao menos neste contexto literário e tecnológico em questão. A Internet, tão onipresente, tem a capacidade de tornar difuso o reconhecimento das próprias fontes de informação, tamanha a imersão dos usuários na pluralidade conteudística.

Dois pontos supracitados contribuem para a intensificação da paratextualidade na EI: as conexões de pontos distantes no espaçotempo e a globalização de culturas locais. As tecnologias contemporâneas de smartphones e de conexão móvel à internet via $3 \mathrm{G}$ e $4 \mathrm{G}$, além da difusão cada vez maior da banda larga via Wi-Fi, contribuem para permitir às pessoas o acesso de informações colocadas online. Tais informações também se multiplicam, auxiliadas pela expansão tecnológica da capacidade de processamento e armazenamento de computadores e dispositivos portáteis. Com isso, leitores

Dossiê Multimodalidade da Memória: Narrativa e Teoria Social

Arquivos do CMD, Volume 4, N.1. Jan/Jun 2016 
têm acesso muito mais facilitado a conteúdos criados sobre o objeto de leitura e podem amiúde fazer pesquisas online para acessar sites com informações relevantes. O dispositivo que os leva ao paratexto está quase sempre ao alcance da mão, seja o celular seja o computador.

A ascensão de uma cultura global, principalmente entre os mais jovens, é o grande canal de acesso e produção do conteúdo online. $\mathrm{O}$ uso do inglês como forma de comunicação entre pessoas de diversos países faz com que se produza muito conteúdo neste idioma, tal quais os produzidos sobre Graça Infinita e House of Leaves $^{2}$. Saber e desejar fazer buscas online em inglês é um exemplo das diversas práticas que estão incorporadas pelos agentes para que os distanciados pontos no espaçotempo possam se conectar e efetivar a rede como ela é; a mera referência ao uso do Google para saciar dúvidas, durante uma discussão qualquer, por exemplo em um bar, já é um dos sintomas de tal cultura global contemporânea.

Um exemplo de condução ao conteúdo: o Google Alerts é um serviço que envia notificações por e-mail sempre que algum conteúdo novo contendo palavras-chave escolhidas pelos usuários é publicado na internet. Alguém que selecionou "Infinite Jest" nesse serviço recebe um e-mail sobre uma notícia de um jornal de Denver, Colorado, EUA (http://www.denverpost.com/), sobre um novo clube do livro (online: http://infinitewinter.org/) dedicado ao tomo de DFW. Na notícia, além de links para o site do clube, também há para diversos outros com conteúdo feito por fãs e dedicado ao livro,

Dossiê Multimodalidade da Memória: Narrativa e Teoria Social

Arquivos do CMD, Volume 4, N.1. Jan/Jun 2016 como um podcast (http://greatconcavity.podbean.com/), uma explo$\begin{array}{lllll}\text { ração } & \text { artística } & \text { das } & \text { cores } & \text { no }\end{array}$

(http://corriebaldauf.com/section/396998-Infinite-Jest-Project.html)

\section{2. (graça infinita ou infinite jest no original)}

Afirmar que o romance não segue regras tradicionais é perder o xis da questão. A estrutura narrativa de Wallace deve ser vista como uma resposta a uma sensibilidade cultural alterada. O livro imita, em seus movimentos e suas cargas densas de dados referenciais, os sistemas distribuídos que são o novo paradigma nas comunicações. O livro não é sobre cultura eletrônica, porém internalizou algumas das energias centrífugas liberadas pelas tecnologias de computador. (Birkerts, 1996, trad. nossa e ênfase no original)

Este livro de mais de 1.000 páginas (com letras pequenas) desafia uma sinopse. Centrado numa escola/academia de tênis de classe alta e numa casa de reabilitação para ex-viciados em álcool e drogas, a narrativa conecta esses dois locais por meio da jornada de um grupo terrorista em busca do filme "Graça Infinita", tão divertido que quem assiste não consegue parar até morrer de sede. A trama é muito fina para tomar tanto conteúdo: o grosso do livro é tomado por uma ultracaracterização dos personagens-quase todos com algum tipo de obsessão ou vício- e por conexões a outras partes do 
livro, triviais ou não, que podem estar a muitas páginas de distância.

O elevado número de personagens fez surgir uma figura na internet que traça as conexões existentes:

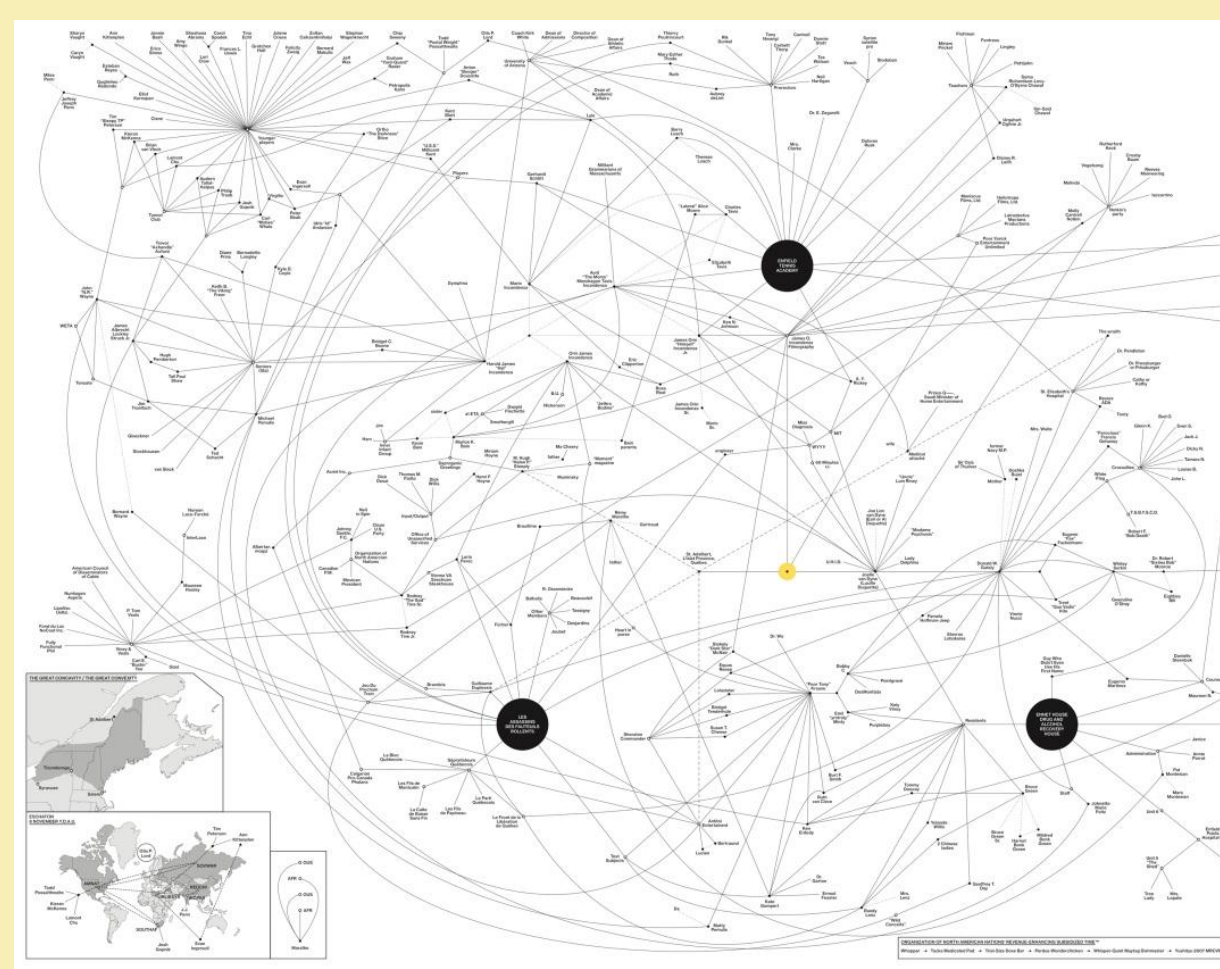

Figura 1-Diagrama de relações entre personagens de Graça Infinita Fonte: http://images.fastcompany.com/upload/IJ_Diagram-HugeA.jpg

Graça Infinita é uma escolha de romance bastante adequada para associar à EI e sociedade em rede: não apenas possui um culto online fértil (nota 1), como sua própria estrutura incentiva a formação desses cultos e replica, de certo modo, a sociedade pósindustrial americana (e global) e as novas geometrias de espaçotempo. A obsessão pelos mistérios contidos às vezes numa frase conduz pessoas a reunirem-se com aficionados na internet; fãs do livro postam teorias em blogs e grupos de discussão. Sua extensão massiva foi utilizada como recurso mercadológico pela editora e seus temas relacionam-se com a busca local pela identidade através de bens de consumo - uma estrutura econômica global de massas-, num gênero classificado como romance maximalista (ERCOLINO, 2012, p. 244 - tradução nossa, ênfase no original):

Um certo procedimento, ou um novo gênero, é então criado duma acumulação quantitativa de detalhes. [...] Numa era de opacidades cognitivas difusas e incertezas existenciais dramáticas, o romance maximalista representa para um grande número de leitores (enquanto consumidores) um tipo sinedóquico do mercado de baixo custo para a "Cultura", um daqueles fervorosamente desejados fetiches de identidade que assombram nossa imagética e orientam nossas vontadesda haute couture francesa e carros italianos até iPhones e iPads.

O culto online a Graça Infinita pode ser entendido então não apenas como uma tentativa de sistematizar a grande quantidade de informações e plasticidade interpretativa do romance, mas também como uma forma de autoafirmação, visto que na EI objetos de consumo são cada vez mais importantes para a definição da identidade. A construção da identidade literária não se restringe aí à relação imaginada com o autor e suas maquinações criativas-estende-se

Dossiê Multimodalidade da Memória: Narrativa e Teoria Social

Arquivos do CMD, Volume 4, N.1. Jan/Jun 2016 
aos debates com outros fãs, mesmo que anonimamente, e ao acesso ao conteúdo criado por eles, dispensando as antigas credenciais de especialistas devido às possibilidades sociais da internet.

As características do romance maximalista listadas por Ercolino-tais quais grande extensão, modo enciclopédico, coralidade dissonante, inter-semioticidade e realismo híbrido-são paradigmáticas da complexificação dos sistemas de informação e comunicação e da realidade circinada ocorrida na EI. Contudo, Graça Infinita não busca apenas mimetizar a realidade pós-industrial: propõe tratar de questões humanísticas muito difíceis de serem postas numa realidade hipercosmopolita; é uma obra que, "para ser crítica, paradoxalmente precisa desfamiliarizar o real, uma vez que numa época de irrealidade difusa a única maneira de representar o mundo é tornando-o quase irreconhecível" (ibid., p. 254, trad. nossa, ênfase no original). Ademais, o advento da televisão como recurso formador de identidade para a geração de DFW (que foi um viciado em TV) trouxe consequências para as obras, como o que ele definiu como "ficção-imagem": uma consequência de se ter nascido numa era onde a TV já estava lá e a vida sem ela não fora experienciada. A $\mathrm{TV}$, para os nascidos dos anos 60 adiante, é parte constitutiva da realidade e fonte de inspiração literária: “o que jovens escritores estão explorando por dados sobre alguma realidade para embasar sua ficção já é composto de personagens fictícios em narrativas altamente formalizadas" (FOSTER WALLACE et al, 2014 [1990], p. 659 - tradução nossa).
Os sentimentos de DFW sobre como é viver numa sociedade midiatizada traduziram-se numa ficção que, apesar de ser grosso modo pré-internet, ganhou sucesso com o desenvolvimento das tecnologias digitais. Não é pouco irônico que seu projeto crítico ao isolamento humano causado pelos entretenimentos encapsulados em telas esteja tão difundido nas próprias telas. Tal tipo de ironia nunca escapou da atenção de DFW e em Graça Infinita os personagens estão imersos na rede de informação saturada, querendo ou não: alienação não é uma escolha; o processo de saída da dicotomia cinismo v. ingenuidade é o desafio anfractuosamente não linear para uma individualidade substantiva.

Como consequência da crença na exposição das massas a um excesso de "experiências simuladas" e de estudos filosóficos como pós-estruturalismo e filosofia da linguagem, DFW tentou-não apenas em sua ficção, mas também em seus ensaios-dissolver a ideia do autor como figura de solidez arquetípica. Em Graça Infinita, isto se dá pela miríade de texto, de personagens, de cenas, de dados, de estilos, de temas; pelo shift caótico do vulgar com o refinado, do academês com o jargão das ruas e dos médicos e dos críticos e dos matemáticos; pela preocupação em ironizar a si mesmo, como quando Steeply e Marathe discutem filosófica e seriamente sobre o amor e em seguida surge a frase "Steeply peidou de leve" (p. 110). DFW, em vida e obra, tentou desmistificar sua escrita como dotada de misticismo analítico-a ironia é que talvez essa própria preocupação ajudou-lhe a ser mistificado. A dissociação autoral pelo lado

Dossiê Multimodalidade da Memória: Narrativa e Teoria Social

Arquivos do CMD, Volume 4, N.1. Jan/Jun 2016 
do autor efetua-se naqueles nascidos nos anos 60 como DFW e MZD pela ideia barthesiana de "morte do autor", reforçada pela vida num mundo permeado de imagens outrora televisivas e agora internéticas. Estar nesse mundo da EI facilita ver menos o autor como uma entidade e mais como uma função, i. é, enquanto ponto inserido nas redes socioculturais que possibilitam a construção de determinado texto literário e o tornam significativo para mais pessoas-os efeitos intelectuais de tal perspectiva compreendem tanto o pós-modernismo literário (MCHALE, 1987, p. 200-201) quanto o pós-estruturalismo que desconstrói o a priori subjetivo cartesiano para ver o sujeito como objeto de uma determinada relação de conhecimento e de poder (FOUCAULT, 1994, p.223). A diluição metafísica da subjetividade está presente também na experiência literária de DFW-Graça Infinita tem seu nome derivado duma cena de Hamlet e a peça shakespeariana é referenciada várias vezes pelo livro ${ }^{3}$; a narrativa amiúde parece não conseguir se situar entre situações absurdamente irrealistas e uma compaixão humanista profunda. Um livro que conseguiu servir tanto como bem de consumo para a geração da internet quanto como bem de produção, na forma de conteúdo online paratextual.

\section{3. (house of leaves)}

"Uma história de amor feita por um semiólogo. Danielewski possui um coração de compositor tão afinado à dor de cotovelo quanto à teoria de Derrida sobre o signo."-House of Leaves, contracapa.
É difícil encontrar uma obra mais mediada ${ }^{4}$ que House of Leaves. A tradução do nome significa "Casa de Páginas" e na obra temos um exercício de seleção ontológica-cabe ao leitor decidir quem escreveu o livro, i. é, no universo do livro alguém o escreveu, e a autoria é disputada: o livro circula sobre eventos envolvendo uma casa cujo interior é maior que o exterior, onde o fotógrafo William Navidson decidiu fazer um experimento "Big Brother", filmando tudo que acontecia na casa. Dessas filmagens saem o alegado primeiro rascunho do livro, escrito por um à la Borges velho cego chamado Zampanó (alusão a um filme de Fellini). Este rascunho é encontrado por um jovem drogado chamado Johnny Truant-ao longo do livro vemos notas de rodapé deixadas por Johnny (em fonte diferente) comentando as passagens de Zampanó, que compõem o texto principal. (Os estilos dos dois são bastante conflitantes: Zampanó é um erudito que prima por sisudez linguística e rigor gramatical, com maestria no academês; Truant emprega fluxos de consciência e aparenta desconsiderar revisões de texto; a paridade de estilos numa mesma obra remete a Graça Infinita e o tema maior do pósmodernismo de misturar a haute couture com o vulgar.) Após Truant, há os misteriosos "editores" que supostamente fizeram uma segunda edição do livro que circulava nos porões da internet do fim do século XX. O número de mediações internas ao livro fez surgir uma figura na internet que dispõe as várias camadas de informação

Dossiê Multimodalidade da Memória: Narrativa e Teoria Social

Arquivos do CMD, Volume 4, N.1. Jan/Jun 2016 
mediada no livro, acrescentando também o elaborador (MZD) e nós, isto é, os sujeitos da experiência do livro:

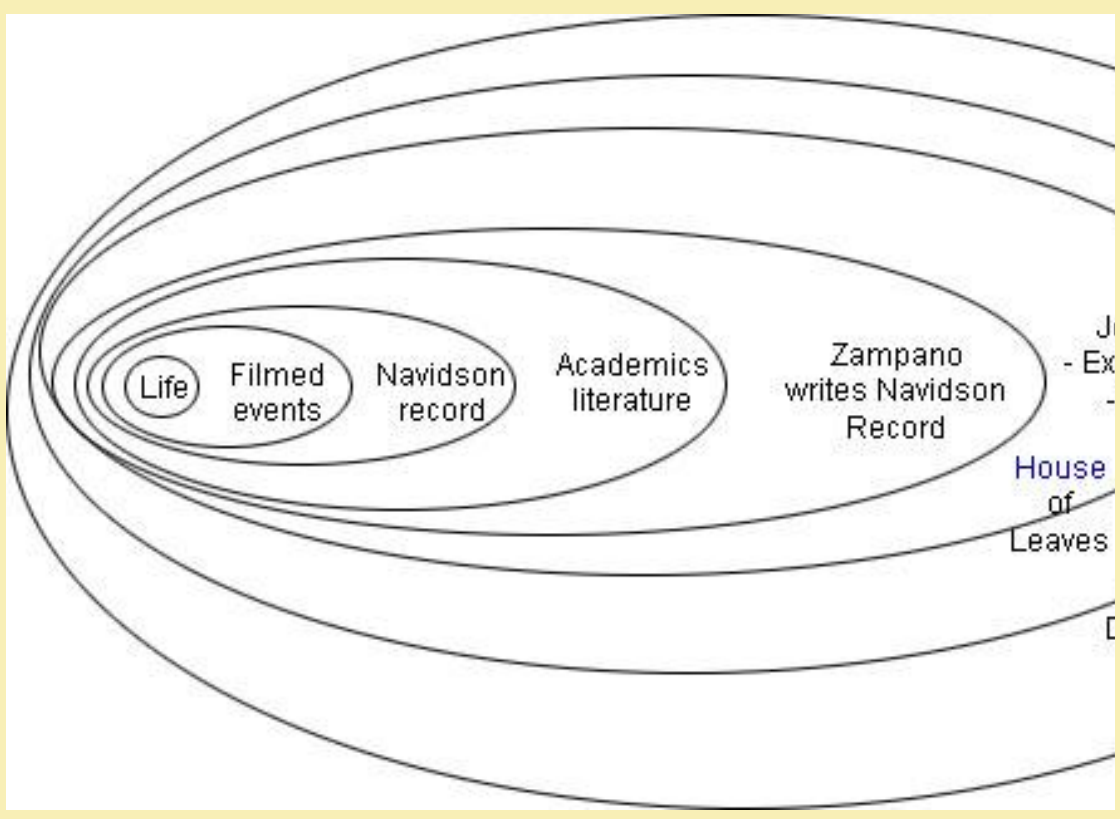

Figura 2 - Camadas mediadas em House of Leave Fonte: http://briancroxall.pbworks.com/f/1225940072/layers.jpg

A figura inclui não apenas as filmagens, mas também a edição delas, indicando que imagens cruas possuem sentidos diferentes de sua versão enxugada e editada. Outra menção interessante é da literatura acadêmica: são incluídas no livro (pelo erudito Zampanó) menções bibliográficas a diversas obras, algumas reais e outras fictícias, umas com a ficção aprimorada pela internet (nota 1). Tais referências bibliográficas são esclarecedoras para mostrar a carga literária tanto de Zampanó quanto de MZD—situam-se em algum ponto turvo da ficção, já que muitas delas não são fictícias e fazem papel igual ao de suas semelhantes na não ficção: mostrar de onde vem certa citação ou conteúdo. As fronteiras da ficção com o real são também eivadas pela referência a pessoas reais no livro, como Stephen King e Jacques Derrida.

Sobre a figura, por fim, é interessante falar da última camada inserida: "nós". A ausência de algo além, como Natureza ou Deusregimes de verdade respectivamente de modernismo e prémodernismo_- é bastante sintomática da experiência subjetiva na EI, pois, com o politeísmo de valores que o cosmopolitismo acarreta, as pessoas tendem a pensar em suas visões de mundo como individuais, contingenciais a outros seres humanos. A imaginação de algo externo estruturado e normativo torna-se subalterna à cognição. O transcendental, na obra de DFW e MZD, é originado dos próprios sujeitos; é, na verdade, imanente. A sociedade cosmopolita de Graça Infinita ou o deslocamento semiótico de House of Leaves exigem a dissolução do transcendente e sua transfiguração para o imanente, uma vez que tais obras tentam criar um logos próprio de funcionamento-são "literatura ergódica", isto é, requerem esforços não triviais e criarem mecânicas de sentido endêmicas.

Uma diferença essencial entre a televisão e a internet é que a primeira não concede ao usuário a possibilidade de interagir com o conteúdo e na segunda o conteúdo é em larga escala formado pelos próprios usuários. Os principais sites sociais como Facebook, YouTube, Twitter, Instagram etc. têm como principal necessidade organizar conteúdo, em vez de produzi-los, como nos canais de TV. A

Dossiê Multimodalidade da Memória: Narrativa e Teoria Social

Arquivos do CMD, Volume 4, N.1. Jan/Jun 2016 
literatura possui uma história mais velha que a internet atual envolvendo interatividade, como a ficção de Jorge L. Borges Examen de la obra de Herbert Quain (1941) onde ao leitor é levantada a teoria de um próprio caminho narrativo a ser seguido, um jogo literário resultando em nove finais possíveis. O jogo da amarelinha (1963), de Cortázar, também concedia discricionariedade interpretativa ao leitor. Mas é com a internet que temos um terreno mais fértil para a criptografia narrativa de House of Leaves: o leitor pode notar sentidos do livro que não perceberia apenas lendo o livro, acessando fóruns, procurando paratextos publicados online. Um dos principais eixos de House of Leaves está em decidir quem escreveu o livroisto é, o livro dentro do livro, e discussões online prosperam, envolvendo passagens do texto com alegados sentidos ocultos-e há diversos indicativos de que ao menos um dos personagens é inventado, Zampanó, Truant, ou mesmo os dois, optando pela ideia de que a esposa de Navidson, Karen Green, o tenha escrito. MZD, em entrevista, corrobora a ideia de um livro de autoria diluída e significado contingencial ao ato da interpretação; House of Leaves não possui "texto sagrado [...]. As noções de autenticidade ou originalidade são constantemente refutadas." (MCCAFFREY e GREGORY, 2003, p.121)

House of Leaves, em sua empreitada por um texto não ortográfico - um que não corrobore a apenas uma determinada cadeia de sentidos-, assevera a singularidade da experiência e sua não transponibilidade para formas encapsuladas por mídias (HANSEN, 2004, p. 605-606). São ecos do projeto de desfamiliarizar o imagético real também visto em Graça Infinita. Este real mediado por diversas tecnologias, no entanto, já possui um ponto de partida problemático formado pelas dúvidas quanto à manipulação de imagens via tecnologia digital (p.3 do livro) - MZD pode não estar realizando uma crítica do real, senão estar apontando para um real implausível ou perenemente controverso: uma cultura informacional póshermenêutica.

\section{4. «por uma hermenêutica neorromântica»}

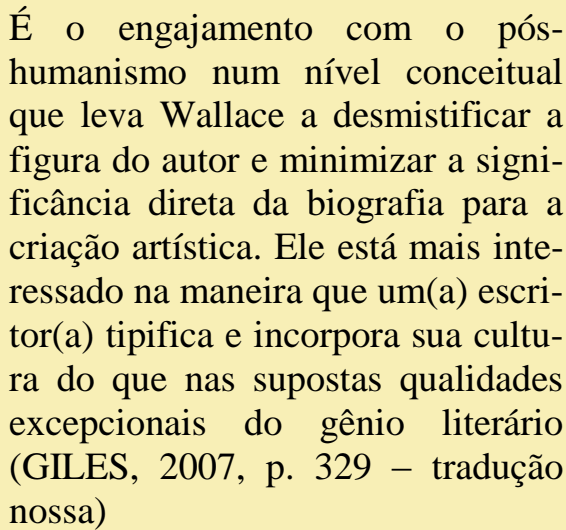

"P

R: Sim, ao escrever ficção sempre penso no leitor que tem lá o seu Google a dois segundos de distância. Às vezes, quando vou colocar uma referência à cultura pop—que na verdade nem sei se posso chamar de cultura pop; é mais uma referência à minha subcultura que nem deve ser tão compartilhada assim pra poder ser jogada a esmo para uma audiência abstrata-, nem me preocupo tanto, por-

Dossiê Multimodalidade da Memória: Narrativa e Teoria Social

Arquivos do CMD, Volume 4, N.1. Jan/Jun 2016 
que o hipotético leitor pode, se quiser, digitar a palavra lá no seu Google e sacar a referência.”

Analisados à luz de seus recursos formais, Graça Infinita e House of Leaves compartilham a crença de que o meio traz mensagens, de que as mídias são tão importantes quanto o conteúdo que carregam e que é possível ao escritor aliar recursos tecno-midiáticos - quer dizer, buscando utilizar estilo e forma como função referencial da linguagem - à comunicação. Quando um personagem está preso e desesperado, o contexto pode envolver um parágrafo grande e frases extensas (recursos estilísticos que imprimem também uma sensação de sufoco); quando há uma cena de ação, há poucas palavras em cada página, fazendo o leitor passá-las rapidamente, dando maior ação também ao leitor. DFW e MZD são autores contemporâneos que vivenciaram o mundo da EI, em contato conspícuo com mídias eletrônicas: DFW era viciado em televisão e o pai de MZD era um cineasta polonês que sempre levou aos filhos discussões sobre o ato de filmar (ver http://goo.gl/CxG2H0).

Os dois livros convergem para uma interpretação da EI como hiperestética, onde a subjetividade está arraigada por imagens aceleradas. Pontos fixos são difíceis de firmarem-se em ambos: Graça Infinita opera com lacunas de enredo e House of Leaves com lacunas ontológicas.

E alguém preenche tais lacunas?

Aparentemente são elas que motivam tantas pessoas a formarem grupos de discussão e produção de paratexto na internet. Os autores, percebendo-se como fragmentados da entidade autoral pelo grande número de mediações com compõem sua experiência de vida - mas que não conseguem apreender como uma realidade plena e inconteste - na EI, acabam com isso transferindo o ato de sacralizar o texto aos leitores ${ }^{5}$. Uma ironia: os autores, tentando escapar da autoimagem de entidade em seus textos fugidios, acabam sendo cultuados por determinados leitores justamente pelo caráter fugidio dos textos. Em fóruns e blogs da internet encontram-se declarações da genialidade de DFW e MZD embasadas pelas sutilezas, obscuridades e esoterismos dos romances, que forçam o leitor a dissecar a obra, em vez de lê-la. A posição dos autores quanto a isso é dúbia como são suas relações com a comunicação; eles preferem não discutir a validade das especulações sobre seus romances, talvez motivados pela crença na dissociação semiótica das obras, uma vez publicadas, de suas personas.

Nesse grupo de leitores e seus séquitos, é possível encontrar o ato interpretativo que chamo de hermenêutica neorromântica. Ao definir o que pode ser chamado de romantismo hermenêutico como a crença no sentido do texto como expressão pari passu da vida interna do autor - isto é, que o sentido do texto é exatamente igual à volição do autor-, a nova roupagem dessa crença são grupos reunidos virtualmente para produzir e receber paratexto sobre obras. $\mathrm{Na}$ versão neorromântica, a interpretação de texto se dá pelo (ou seja, pela crença em) sentido como volição do autor mais sentidos levantados no paratexto - a grande novidade da EI para esse tipo de

Dossiê Multimodalidade da Memória: Narrativa e Teoria Social

Arquivos do CMD, Volume 4, N.1. Jan/Jun 2016 
hermenêutica está na acessibilidade de produzir e acessar conteúdo de terceiros sobre obras, pela miríade de informações e sites disponíveis na internet. Leituras são interrompidas para uma busca no Google, via celular, tablet ou computador. Imagens (como a figura 1 e a 2) são elaboradas.

O tema central (supõe-se) de House of Leaves é alegórico ao conceito de hermenêutica neorromântica: uma casa cujo interior é maior que seu exterior. Em termos semióticos, a internet funciona como o interior desta casa que externamente é o texto como encontrado nos livros. A hermenêutica neorromântica prescreve o sentido coletado como a intenção do autor somada ao cruzamento de pontos da rede sociocultural no "ponto leitor"-principalmente o paratexto viabilizado pelas tecnologias da Era da Informação.

Em 1990, DFW escrevia sobre uma sociedade que não constituía mais uma comunidade por compartilhamento de valores. O consumo comum de imagens havia se tornado um aspecto mais determinante da identidade coletiva. E agora, que o caso se abre para uma sociedade com formas de receber imagens em comum? Os produtores de conteúdo são tantos que não temos algumas autoridades legislando sobre as "boas imagens". Os legisladores são profissionais de tecnologia da informação. Os efeitos sobre a formação da identidade ainda estão em estágio inicial. Talvez, nesse sentido, haja uma presciência de Graça Infinita e House of Leaves, com suas lacunas: a exposição massiva a mídias carregando miríades de conteúdos conduzirá a uma subjetividade cada vez mais existencial, com o ato de escolha dentro do supermercado de crenças mais e mais consciente e não determinístico. Tais livros conferem ao leitor a liberdade de escolher, dentro do texto, o que é trivial e o que é importante- talvez até suas mecânicas sejam arbitrárias.

Por razões tecno-midiáticas, este ensaio tentou representar alguns conceitos formais de Graça Infinita e House of Leaves: as notas extensas com conteúdos importantes são parte da textura de Graça Infinita, a representar um mundo saturado de informações, um labirinto de valores; House of Leaves convida o leitor a ser a autoridade ontológica do texto, assim como o ensaio convida a julgar a semificção da parte zero e o que ela significa ontologicamente- - se é real ou não, e em que grau. A Era da Informação, por meio de suas redes que conectam pontos distantes no espaçotempo, corrobora para a efemeridade dos próprios pontos: leitores e escritores se perdem na maré informacional: “antes mundo era pequeno, porque Terra era grande; hoje mundo é muito grande, porque Terra é pequena".

\section{Notas}

1. Uma experiência pessoal exemplifica uma dimensão do pós-humanismo bastante presente nos livros aqui discutidos: o nivelamento de coisas - ou humano trazidos por coisas - ao status de significância dos humanos. Enquanto habitante de uma cide relativamente mais cosmopolita em conversas com an habitante o umigos e pessoas de mesma classe social muitos temas engajados com interesse tratam de pessoas ou fenomenos fundamentados por informação mediada por meios de comunicação em que ninguém teve um contato empírico com a raiz do assunto As reuniões de parentes numa cidade pequena do interior, que visito anualmente, sempre me chamaram a atenção por quase sempre os assuntos dizerem respeito a pessoas imediatamente ao alcance do diálogo e do conhecimento pessoal delas-

Dossiê Multimodalidade da Memória: Narrativa e Teoria Social

Arquivos do CMD, Volume 4, N.1. Jan/Jun 2016 
assuntos de fonte não interpessoal como "política nacional" ou "entretenimento" foram bem mais raros nessas comunicacões interioranas. Talvez isso seja indicativo de que, quanto mais a metropolização despersonaliza as relações (Simmel, 2009) ou as toma mais funciolmente específicas (Parsons, 1939), maior a im2009) ou as tor mais funcionlo "preen a importância que as pessoas dão, para "preencher lacunas de identidade", a fenômenos mediatizados. Neste sentido pós-industial, são significativas obras como Graça Infinita onde os personagens têm sua identidade definida pelo que consomem e como House of Leaves onde o leitor pode selecionar o que existe ou não, dentro do universo narrativo. A frase da escritora do romance maximalista White Teeth, Zadie Smith, também é sintomática: "Não é tarefa do escritor dizer-nos como alguém se sentiu sobre algo; é dizer-nos como o mundo funciona" (apud Wood, 2000, trad. nossa).

2. UMA TOPOGRAFIA VIRTUAL DE...

GRAÇA INFINITA : A semificção da parte zero deste ensaio exibe certos campos de vetores que leitores percorrem na internet para acessar paratexto relacionado a Graça Infinita: por meio do Google é possível encontrar uma infinidade de sites com conteúdo relacionado ao livro. Esses sites podem conter links para outros sites, iniciando uma cadeia de conteúdo.

O YouTube - terceiro site mais acessado do mundo depois de Google e Facebook (fonte: http://goo gl/BC40CR; todos os sites doravante dispostos form acessodos

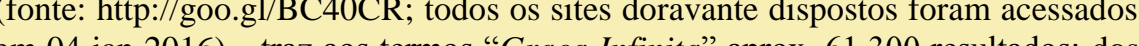
em 04 jan 2016) graz aos ter primeiros vine videos, treze são sobre o livro, sendo que quase tous são vídeos criados por "BookTubers" - pessoas que publicam vídeos sobre livros no YouTube com frequência-e há um vídeo da editora (Cia. das Letras) protagonizado pelo tradutor do livro, Caetano Galindo. O primeiro vídeo da lista ${ }^{a}$, da BookTuber "tatianagfeltrin", possui 26mil visualizações e também comenta sobre outros dois livros de DFW. Tatiana possui $162 \mathrm{mil}$ inscritos em seu canal. "Infinite Jest" traz aprox. 30.300 resultados, lembrando que "jest" é uma palavra pouco usual, levemente arcaica. Interessante notar que para os resultados em inglês, o nível de paratexto é bem maior na página inicial: há não uma mas duas sketchs cômicas pan o é be live con penco o livo con numa delas o live clube do livro-; há um ensaio narrado, un trecho do livro en andio, entrevistas do autor sobre o livro etc. Tudo isso na primeira página da pesquisa do YouTube. Mas no universo dos sites apontados pelo Google na primeira página de busca "Infinite Jest", o que mais chama a atenção é sua Wiki particular (http://infinitejest.wallacewiki.com/), um site de conteúdo editável por qualquer pessoa disposta a se registrar. Aparentemente uma ou mais pessoas dispuseram-se ao anonimato e contribuíram para criar uma massiva gama de paratexto, tendo elaborado um guia página-a-página das mais de mil páginas do romance. A tarefa aparenta ser tão obsessiva quanto o próprio romance, p. ex.:
"Kekuléan" is not a type of knot. To Hal, the knot he is focusing on resembles the self-consuming, annular shape of the snake that inspired August Kekulé's discovery of benzene's molecular structure. August Kekule (1829-1896), a renowned German organic chemist, was the principal founder of the theory of chemical structure. His most famous work, the discovery of benzene molecule's structure, is said to be inspired by dream. "Kekulé's Dream" was that of a self-devouring snake, the shape of which he used to describe the benzene ring.

\section{Page 5 "I stare carefully into the Keku-}

\section{léan knot of the middle Dean's necktie."}

Dossiê Multimodalidade da Memória: Narrativa e Teoria Social

Arquivos do CMD, Volume 4, N.1. Jan/Jun 2016 


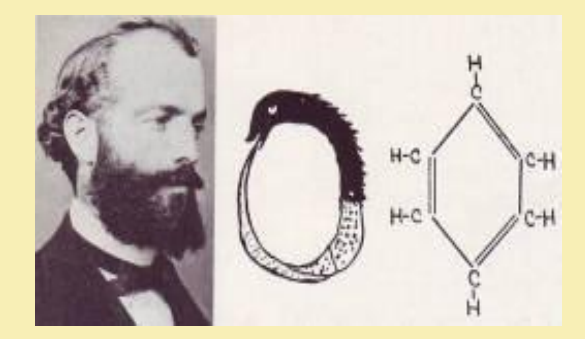

[Figura 3 - August Kekulé]

August Kekulé (left), the self-consuming snake (middle) and the benzene molecular structure it inspired (right)

Dossiê Multimodalidade da Memória: Narrativa e Teoria Social

Arquivos do CMD, Volume 4, N.1. Jan/Jun 2016 
Hal's intense focus on this annular, or ring-like, part of the tie is the first reference to annular shapes.

site Infinite Summer (http://infinitesummer.org/) foi um clube do livro virtual do ano de 2009, que reuniu várias pessoas (virtualmente) para ler Graça Infinita num ritmo coletivo e discutir as percepções de cada um em fóruns. O site contava também com "guias convidados" que faziam postagens especiais e possuíam as credenciais tácitas de especialistas. Em 2016, há uma nova empreitada de clube virtul para dispor pessoas a lerem 75 páginas por semana e discutirem online: Infinite Winter (http://infinitewinter.org/).

Quem está interessado nas várias referências ao longo do livro ou em juntar o Quem está inte Winter (hit//infiritewis longo do quebra-cabeças do encdo e do elenco circinados pela narrativa não linear poderá facilmente encontrar conteúdo online. Não precisará necessariamente comprar outros livros escritos por especialistas acadêmicos - como os guias de Ulyssesapesar de que tais livros continuam sendo feitos: Graça Infinita tem livros paratextuais como o de Stephen Burn (2003) da Universidade de Glasgow, e o de Greg Carlisle (2007), professor no Kentucky.

HOUSE OF LEAVES: no YouTube os termos conduzem na primeira página a algumas resenhas do livro; a uma música de horror/suspense disponível para uso sob licença Creative Commons (de relação com o livro no mínimo de gênero); c̃es contendo texto cinético, dialog livro; a uma curta entrevista com MZD sobre o livro; a uma das músicas de sua irmã Poe; e à introdução do livro em formato de áudio, aparentemente gravada por um fã.

Na contracapa e na primeira página, a que contém informações editoriais, o livro fornece os endereços de dois sites: www.realpoe.com e www.houseofleaves.com. Aquele conduz a um site "em construção", com uma animação em Flash e links para quatro redes sociais: Instagram, YouTube, Facebook e Twitter. Trata-se do site da cantora Poe, irmã de MZD, que apesar de não ter conteúdo no site oficial, possui bastante nas redes sociais - diversos clipes seus no YouTube possuem milhares de visualizaç̃es. Poe foi uma das primeiras artistas a dialogar com fãs em comunidades online e lançou um álbum " "Haus l") acessio a House of Leaves (que também contém referêncins à i ( "Haña, alcm do link para o site).

outro site, homônimo ao livro, agora conduz para markzdanielewski.com. House of Leaves foi o primeiro livro de MZD - talvez com o advento de mais livros, ele optou por um site com seu nome para abarcar conteúdo sobre todas suas obras. O início do site é uma grande propaganda de seu último, em formato de vídeo no YouTube. Este é um bom exemplo de experiência multimídia, tema de House of Leaves: uma condução do livro ao site, que conduz para outro site que contém um vídeo hospedado em outro site.

E por esse site chegamos a talvez o principal centro de criação/indicacão de

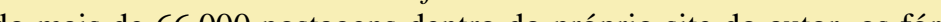

atividade desde 2000 e congregam aprox. 90.000 usuários registrados, que discutem teorias sobre o enredo e elenco, além de (re)produzirem conteúdo como a informações sob

Outro site, navidson-files.org, criou conteúdo fictício citado no livro como se fosse real. A porção do livro "escrita" por Zampanó que simula um texto acadêmico com várias citações bibliográficas, muitas delas inexistentes, ganha contornos de veracidade com a ajuda deste site, que é uma espécie de arquivo com várias fotos "escaneadas" de livros falsos. O universo do livro é expandido pelo site, que também tenta simular que o filme sobre o qual o livro é escrito-The Navidson Record -é real. De autoria desconhecida, fica a dúvida se o site teria sido criado por MZD, para ampliar a imersão dos leitores, ou por fãs que querem expandir a história ${ }^{\mathrm{b}}$.

Graça Infinita e House of Leaves possuem tanto conteúdo na internet que muito provavelmente o que foi falado sobre os livros ultrapassou o número de palavras dos próprios livros. Por meio do Google, o interessado encontra tais discussões e conteúdo secundário (paratexto) com facilidade, muitos deles criados a quilômetros e anos de distância. Nesses casos, o emissor do conteúdo importa menos que a relação que o interessado faz dos conteúdos com sua experiência do livro: un caldo interpretativo que chamo de hermenêutica neorromântica ${ }^{\mathrm{c}}$.

É bastante provável que o YouTube utilize algum algoritmo que hierarquiza os resultados de busca de acordo com o histórico do usuário; os vídeos já assistidos e no idioma natal parecem ter prioridade (não confirmada) —o vídeo de Tatiana apareceu-me em primeiro lugar numa pesquisa dos termos "Infinite Jest". Os algoritmos de discriminação de conteúdo estão ficando cada vez mais eficientes em descobrir no que o usuário se interessa e em mostrá-lo logo na página inicial (vide Amazon, Facebook e YouTube).

b. $\quad$ A expansão do universo de livros de ficção por fãs não enA exice Anazon, Facebolo e YouTube).

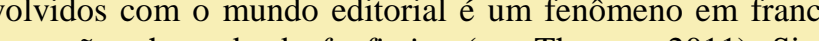
ascensão, chamado de fanfiction (ver Thomas, 2011). Sites como wattpad.com congregam diversas estorias sobre desde Harry Potter e Percy Jackson a Justin Bieber e One Direction. As "fanfics" também passaram a denotar estórias utilizadas para expandir, em vez duma criação literária, uma causa política: no Facebook proliferaram "fanfics de esquerda" (ver http://goo.gl/dH1pfE), onde é contada uma estória com ares de relato verídico para incentivar determinados valores. Há pessoas que comentam e reforçam a veracidade, dizendo "eu estava lá”. Foi criada no Facebook, uma pág. dizeníro "eu estava lá. Foi criada no Facebook, uma págin satíca especialmente dedicada a expor supostas historias (hilps (https://goo.gl/qZHqup). A fluidez entro fato e ficção atinge limites surpreendentes em tal assunto, afinal, é difícil obter

Dossiê Multimodalidade da Memória: Narrativa e Teoria Social

Arquivos do CMD, Volume 4, N.1. Jan/Jun 2016 
certeza do que é uma fanfic e o que é um relato genuíno sobre uma vivência—que por si já é um conceito dúbio—-ainnimizam a própria importância desse questionamento.

Ver parte 4.

3. A anti-interioridade de Graça Infinita parece estar relacionada a uma interpretação peculiar da peça. Freudenthal define anti-interioridade como "um modo de Jentidade fundado no mundo material de tanto objetos quanto corpos biológicos despojado de uma no espiritual" (2010, p.192), a autora sustenta que Graça Infinita propõe, em vez de mostrar como a cultura comercial erradica a subjetividade, mostrar a (re)formação contínua e contingente da identidade perante a realidade materia externa — o que remete à aceleração comunicacional da EI e aos métodos e crenças pós-modernos/estruturalistas. Esta apreensão corresponde a uma forma específica de leitura da peça de Shakespeare:

Quem é Hamlet? Numa visão corriqueira, o leitor/espectador da peça poderâ encarar o príncipe como uma figura melancólica frente a diversos problemas da vida (morte, hipocrisia, etc.), tendo que lidar com a "chusma de fingidos". Ess

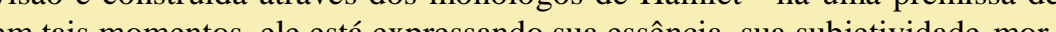

oct Ocorre que é bastante plausivel obstrar Hamlet sem distinguir seus discurso solitários daqueles momentos sociais quando se comporta de maneira peculiar e variável (p. ex. imitando os personagens com que lida) - seriam modos de subjetivação com o mesmo grau de importância para a construção da persona. Tendo em conta seu comportamento frente a Polonius ou Ofélia (ver as diferenças pré e pós-morte), Hamlet se encaixa no paradigma da anti-interioridade, deslocando seu Eu para vários platôs, de acordo com o contexto. A mecânica de Graça Infinita é bastante semelhante: a caracterização dos personagens e seus fluxos emocionais são articulados em relação a objetos externos multiformes- o polimorfismo das cenas e consequentemente dos persongens provoca um continu impedimento de formac̃a (ou contínu duebra) de imagens estáticas sobre os aspectos identitários.

4. Há um paradoxo nos usos do verbo mediar (em inglês mediate), que significa aqui basicamente a comunicação entre emissor e receptor que possui canais/emissores secundários, terciários, quaternários etc. No ensaio $E$ Unibus Pluram, de 1990, DFW afirma que a qualidade da comunicação com a qual um americano gastava em média $6 \mathrm{~h}$ por dia-i. é, a televisão - era inconscientemenfinal o objetivo dos canais é fazt possível. A preocupação de DFW era com a autenticidade daquela mensagem emitida pela televisão, altamente mediada para atender ao objetivo de entreter, onde fingir que não era uma mensagem mediada - p. ex. via atuação - é um importante recurso. Olhando para a TV e sua lógica de produção de conteúdo, é fácil compreender as críticas desconstrutivistas que buscam acentuar o caráter mediado e artificial do conteúdo televisivo. Ele é dúbio na relação experiência v. eficiência comumente associada à aparência de espontâneo.

Mas essas críticas começam a ficar muito problemáticas com o advento da internet. Numa era onde quase todos os inseridos estão criando conteúdo e a relação não é mais de uns poucos criadores para uma massa amorfa e incomunicativa como fica o status da subjetividade? Se o caso em 1990 de DFW era de subjetividade suprimida pelas relações mediadas com a TV, na internet temos um nivelamento da subjetividade com os meios digitais.

Chega-se ao paradoxo. Quando se está anunciando uma informação como mediada, vem à mente uma emissão original com complexidades comunicativas. Mas quando você está lidando com um universo saturado de tais mediações, é razoável falar de uma fonte original, de um produtor autêntico de conteúdo, quando a tecnologia digital suprimiu a corra ${ }^{0}$ antógica da tecnologia com o copo (Hansen, 2004, p. 623)? Acaba que a0 anuniar um (Hansen, 2004, p. 623)? Acaba que ao antiar un conteúdo como mediado, citica-se a veracidade ao acrescentar mais informaçðes sobre o conteúdo: ao saber mais sobre um conteúdo, estamos de fato sabendo menos ${ }^{\mathrm{a}}$.

a. Por exemplo, em abril de 2014 houve ofensas racistas ao jogador de futebol Daniel Alves envolvendo uma banana jogaga ao cano. Pouco depois o jogador Neymar publicou em da ao campo. Ponco depois o jogador Neymar publicou em seu Instagram uma foto com seu filho, segurando uma banan e com a hashtag \#somostodosmacacos. A publicação alavancou uma onda de fotos de celebridades segurando bananas replicando a hashtag \#somostodosmacacos. A ação de Neymar acabou sendo atribuída a uma agência de publicidade, que elaborou toda a ideia da hashtag e da foto. Ao tomarmo conhecimento do anti-racismo como estratégia de marketing, a mensagem fica mais fraca porque ficamos sabendo que que impulsionou o Neymar não foi somente sua vontade, ma tambén. tambén interesses escusos. Na vercide, há um impasse en definir uma causalidade. a saturação midiática conduz a não querer resolver o misterio -ou a declarar que não há mistério algum - da ação como anti-racismo ou como marketing pessoal. Decerto que ela pode ser as duas coisas, mas temo então o paradoxo, com a complexificação das relações identitárias seja de coisas ou pessoas: quanto mais conexões de identidade algo possui, menos possível é encontrar algo que a caracterize como sendo o que ela é em relação ao resto do mundo Como a história do estudante de sociologia que aprende sobre desiguldades raciais com um viés antiracista e começa a relacionar seus estudos ao dia-a-dia e ño passa a se questionar se ele não estava se tornando racista.

Dossiê Multimodalidade da Memória: Narrativa e Teoria Social

Arquivos do CMD, Volume 4, N.1. Jan/Jun 2016 
5. Um aforisma de Nietzsche, de Humano, demasiado humano (1878, §181), ilumina a questão:

Duas espécies de desconhecimento. O infortúnio dos escritores agudos claros é que os consideramos rasos, e por isso não lhes dispensamos maior esforço; e a sorte dos escritores obscuros é que o leitor se ocupa bastante dees e lhes credita o prazer que tem com sua própria diligência.

As lacunas dos livros servem como artifício para o entretenimento especulativo dos leitores, e Nietzsche considera um desconhecimento creditar ao autor seus As leus o os levam a exaltar as obras online e compartilhar suas ideias conn uma audiencia amiúde abstrata. Talvez seja o que Jameson chama de comoditização da cultura do capitalismo tardio (ver 1991), este período marcado por uma identidade moldada por mercadorias, onde "literatura pesada e esotérica" como Graça Infinita e House of Leaves são apreendidas como válvulas de escape, ironicamente bens de consumo para quem não gosta de bens de consumo.

$\mathrm{O}$ que parece ser o caso no aforisma de Nietzsche - e compartilhado por DFW e MZD nas suas concepç̃es sobre literatura e autoria —é uma visão hermenêutica onde autores e leitores não s̃̃o entidades, mas funcões inseridas no contexto ociocultural que condiciona ine entidact 位o mediadas pelo cotidiano.

\section{Referências Bibliográficas}

ANTONIO, Robert. "After Postmodernism: reactionary tribalism". In: American Journal of Sociology vol. 106 n. 1: 2000. Download de www.jstor.org em $30 \mathrm{dez} 2015$.

BAUDRILLARD, Jean. Simulacros e simulação. Lisboa: Relógio d'Água, 1991.

BAUMAN, Zygmunt. Modernidade líquida. Rio de Janeiro: Zahar, 2001.

BIRKERTS, Sven. "The Alchemist's retort". In: The Atlantic, fev. 1996. Disponível em: http://goo.gl/RIv3QZ acesso em: $16 \mathrm{fev}$ 2016

Dossiê Multimodalidade da Memória: Narrativa e Teoria Social

Arquivos do CMD, Volume 4, N.1. Jan/Jun 2016
BURN, Stephen. David Foster Wallace's Infinite Jest: A Reader's Guide. Nova Iorque: Continuum, 2003.

CARLISLE, Greg. Elegant complexity: a study of David Foster Wallace's Infinite Jest. Los Angeles: SSMG, 2007.

CASTELLS, Manuel. A sociedade em rede. São Paulo: Paz e Terra, 1999a.

O poder da identidade. São Paulo: Paz e Terra, 1999b.

Communication power. Oxford, Nova Iorque: Oxford University Press, 2010.

DANIELEWSKI, Mark. House of Leaves. Nova Iorque: Pantheon Books, 2000.

ERCOLINO, Stefano. "The maximalist novel". In: Comparative Literature vol. 64 n. 3, pp.241-256, 2012

FOSTER WALLACE, David et al. "E Unibus Pluram" [1990]. In The David Foster Wallace reader. Nova Iorque: Little, Brown, 2014.

FOSTER WALLACE, David. Graça Infinita. Tradução de GALINDO, Caetano. São Paulo: Cia. Das Letras, 2014.

Infinite Jest. Nova Iorque: Little, Brown, 2006.

FOUCAULT, Michel. Dits et écrits IV. Paris: Gallimard, 1994.

FREUDENTHAL, Elizabeth. "Anti-interiority: compulsiveness, objectification, and identity in Infinite Jest". In: New Literary History vol. 41 n.1: 2010. Download de www.jstor.org em 10 set 2015 GILES, Paul. "Sentimental posthumanism: David Foster Wallace". In: Twentieth-Century Literature vol. 53 n.3: 2007. Download de www.jstor.org em 10 set 2015.

HANSEN, Mark. "The Digital Topography of Mark Z. Danielewski's 'House of Leaves"'. In: Contemporary Literature vol. 45 n.4 2004. Download de www.jstor.org em 22 set 2015.

JAMESON, Fredric. Postmodernism, or the cultural logic of late capitalism. Durham: Duke UP, 1991.

LATOUR, Bruno. Reassembling the Social. Cambridge: Cam bridge University Press, 2005.

MCCAFFERY, Larry; GREGORY, Sinda. "Haunted house - an interview with Mark Z. Danielewski”. In: Critique vol. 44 n. 2, pp 99-135, 2003.

MCHALE, Brian. Postmodernist fiction. Londres: Routledge, 1987. 
NIETZSCHE, Friedrich. Humano, demasiado humano: um livro para espíritos livres. São Paulo: Cia. de Bolso, 2005.

PARSONS, T. "Professions and Social Structure". In: Social Forces vol. 17 n. 4, pp. 457-467, mai. 1939.

SIMMEL, Georg. As Grandes Cidades e a Vida do Espírito. Covilhã: Lusosofia, 2009.

THOMAS, Bronwen. "What is fanfiction and why are people saying such nice things about it?". In: StoryWorlds: A Journal of Narrative Studies vol. 3: 2011. Download de www.jstor.org em 22 set 2015.

WOOD, James. "Human, all too inhuman" In: New Republic, 2000

Disponível em: https://goo.g1/K44Ny2 acesso em: 04 jan 2016. 